\title{
Immigrants' demand for informal and formal education: evidence from US time use data
}

\author{
Nicola D. Coniglio ${ }^{(1)}$, Rezart Hoxhaj ${ }^{(2)}$ and Hubert Jayet ${ }^{(3)}$ \\ Accepted version at Journal of Demographic Economics
}

\begin{abstract}
This paper contributes to the migration literature studying the time devoted to educational activities. It uses U.S. time-diary surveys to study the allocation of time to informal as well as formal learning and educational activities by immigrants and natives. We develop a simple theoretical framework, which highlights the different constraints/opportunity costs faced by immigrants as compared with natives. Consistently with our theoretical model, the estimates show that immigrants are more likely to engage in informal and formal education and, conditional on participation, they allocate more time to these activities. We find that the main drivers are economic incentives, mostly in the early phase of working life, and that the differences between natives and immigrants persist across generations. We also find that differences between immigrants and natives are generally larger in informal education than in formal education. The investment in informal and formal learning and educational activities is likely to boost immigrants' human and social capital and contribute to their socio-economic integration.
\end{abstract}

Keywords: human capital; informal education; immigrants; time use; U.S.

JEL Code: J15, J22, J24, I20

\author{
Author contacts: \\ (1) Corresponding author: Nicola D. Coniglio, University of Bari Aldo Moro, Largo Abbazia S. \\ Scolastica, 70124 Bari (Italy), Email: nicoladaniele.coniglio@ uniba.it \\ (2) Ghent University and UNU-CRIS, Department of Economics and CESSMIR, Email: \\ rezart.hoxhaj@ugent.be \\ (3) Hubert Jayet, Lille Economie et Management (LEM), University of Lille and CNRS, 59655 \\ Villeneuve d'Ascq Cedex, Lille (France), Email: hubert.jayet@univ-lille.fr
}

\section{Acknowledgements}

Rezart Hoxhaj has received funding from the European Union's Horizon 2020 research and innovation programme under the Marie Sklodowska-Curie grant agreement No 892032.

The authors wish to thank participants in the following seminars and conferences: University of Lille, University of Modena-Reggio Emilia, CREA Luxembourg, European University Institute, International Conference on Economics of Global Interactions (Bari, Italy). 


\section{Introduction}

The socio-economic impact of immigration strongly depends on the human capital and skills of immigrants that are formed both before and after migration. The research community has devoted particular attention to the initial differences between immigrants and natives with respect to several outcome variables such as wages, labor market participation, occupational choices, crime rates, use of welfare support schemes, fertility, gender gaps as well as to their relative dynamic evolution or assimilation processes. Less attention has been devoted to the processes that lead to the observed outcomes and the resources allocated to them.

In this paper, we study the time allocated to formal and informal education by immigrants and natives in the U.S. We define formal education as the whole set of activities linked to participation in courses organized by an educational institution and informal education as all the activities that have a formative content and are performed outside the formal educational system. Informal education includes, for instance, taking a class for personal interest or extracurricular club activities. These activities generally require, and at the same time stimulate, cognitive abilities of participants. They can also be defined as educational leisure as often there is both a strong consumption element and a productive one. These activities are also closely related to lifelong learning and are increasingly important, considering rapid technological changes and automation of production processes (OECD 2014). To our knowledge, this is the first study that analyzes immigrants' decisions to invest in informal and formal education using time-use data and that investigates the process of assimilation in terms of both educational activities over time.

For immigrants, the investment in education, particularly informal education, might represent a fundamental channel for accumulating human capital but also for socio-economic integration. In addition, these human capital enhancing activities generate individual-level as well as community-wide returns ${ }^{1}$. In their decision to invest in human capital, immigrants face different constraints compared to natives. As barriers to formal educational channels might be

\footnotetext{
${ }^{1}$ Educational and training activities outside formal channels are important ingredients of human capital enhancement for broad groups of workers. These investments of time and resources in general improve employment opportunities and might lead to higher wages. According to Fahr (2005), formal education accounts only for a limited part of the required knowledge in the labor market.
} 
particularly high ${ }^{2}$, informal education might represent the only real channel for investing in human capital in the host country. Also, the opportunity cost of investing in these activities might diverge as the time allocated to non-market-activities is closely related to the shadow price of time and to the productivity of consumption time (Becker 1965). Informal education can also be considered as an investment in social capital as, compared to natives, the density of immigrants' social networks is limited (Coleman 1988).

In the first part of the paper, we present a theoretical model on individuals' allocation of time to education and other competing activities which serves as the main background for our empirical analysis. We show how the optimal trajectory in terms of time devoted to educational activities depend, among other things, on the costs and returns to education and the initial level of human capital.

Immigrants are more likely to have higher returns to education in addition to a generally lower initial level of human capital; this is particularly true given the well-documented imperfect degree of transferability of human capital across borders. We expect that these factors positively impact both the propensity to engage and the intensity of participation in educational activities. On the other hand, the cost of engaging in these activities might be higher for immigrants compared to natives, for instance due to language barriers that reduce the effectiveness of learning. In the theoretical model we also emphasize the role of time preferences, which might also significantly differ between immigrants and natives (Goldbach and Schluter 2018; Nowotny 2014; Gibson and McKenzie 2011).

In the second part, we test the main predictions of the model using the American Time-use dataset (ATUS) for the period 2003-15. One of the important novelties of our approach is the use of time allocation data. As argued by Hamermesh and Pfann (2005, page 2) "no other sorts of data allow us to analyze the determinants of how people allocate time outside the labor market". This approach is able to shed more light on the process of immigrant's assimilation than previous studies as it focuses on both participation and the intensity immigrants engage in human capital formation activities at destination, rather than analyzing the effect of human capital levels (e.g. educational attainment, language attainment etc.) on socio-economic assimilation of immigrants. We show that foreign-born ${ }^{3}$ persons are more likely to engage in informal and formal education and, conditional on engaging, they spend more time on these

\footnotetext{
${ }^{2}$ High barriers to formal education for immigrants might be, for instance, related to costly and lengthy recognition procedures or to limited proficiency in the host-country language.

${ }^{3}$ We use the term immigrant and foreign-born interchangeably in this paper.
} 
activities than natives. These differences between the foreign-born and natives are generally larger in informal education than in formal education. As we are focusing on adults that have already made their decision over formal education when young, these findings show that informal education is fundamental in the process of investing in host-country specific human (and social) capital. Finally, we provide evidence of a slow assimilation process with natives in both educational activities, and that some differences carry on to second-generation immigrants.

Our paper contributes to the literature on the educational investments and, more generally, on skill acquisition of immigrants in the destination countries (see Dustmann and Glitz, 2011, for a review). This literature argues that usually education and skills acquired in the home country are not always fully transferable at destination and immigrants need to further invest in education and training to acquire host-country specific skills (Chiswick and Miller 2008; Chiswick 1978). Recent studies on several countries - such as Mattoo et al. (2008) on U.S. and Green et al. (2007) on Australia - find that differences in educational attainment and skill mismatch are at the basis of observed differences in economic outcomes between immigrants and natives. Borjas (2015) finds a lower economic assimilation of recent cohorts of immigrants in the U.S., which depends heavily on the decline of human capital accumulation (i.e. English language skills). Chiswick and Miller (2012) show that the degree of earnings assimilation depends on the skills transferability - proxied by language distance - and on the time immigrants spend in the destination country. They find that immigrants being more similar to natives in terms of skills, experience a lower growth of their earnings due to a decreasing rent over time. Conversely, over time, immigrants endowed with less transferable skills, experience a higher growth in earnings due to accumulation of skills relevant for the destination labor market.

Our study is also related to a limited number of recent contributions on the time-use of immigrants (see Ribar 2012 for a survey). Significant differences between immigrants and natives in time allocated to 'assimilation activities' (purchasing, education, work) are highlighted by the important contribution of Hamermesh and Trejo (2013). Using ATUS data, they show that immigrants are less likely to undertake assimilation activities, but those who do engage in such activities spend relatively more time than natives. They rationalize these findings on the basis of a theoretical framework in which immigrants experience both higher fixed costs and higher returns from time devoted to assimilation activities. An interesting study carried out by Zaiceva and Zimmermann (2014) shows, using data on a sample of immigrants and native women in the United Kingdom, that, compared to white women, non-white-women 
(mainly those originating from Pakistan and Bangladesh) spend significantly more time on food management and particularly religious activities. The study employs a double-hurdle model that jointly analyses the decision to engage in a particular activity (namely childcare, food management and religious observance) and time devoted to it. More recently, Caparrós Ruiz (2017) has investigated immigrant workers' time-use in Spain, a country that has experienced a sudden and large increase in its immigrant population. In this study, important differences between immigrants and natives in the allocation of time to a broad set of categories emerge. Male immigrants from outside the EU are found to invest more time in studying and other activities related to training.

The only study on the determinants of time allocated to informal education activities is, to our knowledge, the analysis conducted by Fahr (2005). Using time-use data for Germany, this study finds evidence of a strong relationship between formal and informal education. However, Fahr's analysis has no specific focus on immigrants.

The paper is organized as follows. Section II describes the theoretical framework from which we derive some testable hypotheses. Section III describes the data used and the empirical strategy we employ in our analysis. Section IV presents the results. Section V summarizes the results and presents the main conclusions of the paper.

\section{Theoretical background}

\subsection{A simple model of education and human capital accumulation}

In this subsection, we present a simple continuous-time model of the optimal trajectories of investment in education and the subsequent accumulation of human capital.

Let us consider an agent living during a finite duration time interval $[0, T]$. At every date $t$, the agent is endowed with $\bar{\theta}$ units of time that can be allocated to three different activities: consumption $\left(c_{t}\right)$, labour $\left(l_{t}\right)$ and education $\left(e_{t}\right)$. We can express the time constraint as follows: $\forall t: l_{t}+c_{t}+e_{t} \leq \bar{\theta}$

Time allocated to labour generates an income $\omega\left(h_{t}\right) l_{t}$, where $\omega\left(h_{t}\right)$ is the wage of the agent, which is a concave increasing function of her current human capital level, $h_{t}$. Following Becker (1965), let us assume that consumption activities are carried out combining time and commodities (that is, goods and services purchased in the market) and that time and commodities are perfect complements. In other words, $c_{t}$ units of time devoted to consumption 
needs $g_{t}=\beta c_{t}$ units of commodities, bought in the market drawing from individual income at price $p$. Then, the agent faces the following budget constraint:

$$
p g_{t}=\beta p c_{t} \leq \omega\left(h_{t}\right) l_{t}
$$

that may also be written as:

$c_{t} \leq w\left(h_{t}\right) l_{t}$

with $w\left(h_{t}\right)=\omega\left(h_{t}\right) / \beta p$

Education contributes to the accumulation of human capital. More precisely, the accumulation of human capital follows the equation:

$\grave{h}_{t}=\operatorname{amax}\left(e_{t}-\varepsilon, 0\right)$

where $\grave{h}_{t}$ is the time derivative of $h_{t}, a$ is the efficiency of education in generating new human capital and $\varepsilon<\bar{\theta}$ is a sunk time cost: only time devoted to education beyond $\varepsilon$ contributes to human capital accumulation.

The agent maximizes the following intertemporal utility function:

$V=\int_{0}^{T} e^{-\rho t} u\left(c_{t}\right) d t$

where $u\left(c_{t}\right)$ is a standard concave increasing instantaneous utility function.

Given our assumption that informal education is not a direct source of utility, the existence of the sunk time cost, $\varepsilon$, implies that either the agent is not involved in informal education $\left(e_{t}=\right.$ 0 ) or devotes $\varepsilon$ units of time at least to informal education. ${ }^{4}$

\subsection{From theory to hypotheses}

The solution of the individual's time allocation choice leads to the determination of optimal trajectories characterized by a pair $\left(e_{t}, h_{t}\right)$, where $e_{t}$ is the optimal choice of education at time $t$ and $h_{t}$ is the current level of human capital (see full details in Appendix 2). For all trajectories, the investment in education $\left(e_{t}\right)$ decreases with time while the level of human capital $\left(h_{t}\right)$ increases. We show that if the agent has a long enough time horizon, at same date $\tau<\mathrm{T}$, the optimal level of education reaches the sunk time cost, $\lim _{t \rightarrow \tau} e_{t}=\varepsilon$, and, from that date on, the agent stops educating: $e_{t}=0$ for $t \geq \tau$.

\footnotetext{
${ }^{4}$ Education often includes activities that can be considered as leisure goods hence producing direct utility to consumers. Here we do not consider the possibility of direct utility from education for simplicity and without loss of generality. The removal of this simplifying assumption would not change the main predictions of the model but would increase the analytical complexity.
} 
Intuitively, the structure of these optimal trajectories is determined by decreasing returns to human capital and the length of remaining life. For an agent to engage in educational activities the future return to human capital generated by education must be positive, the cost being more than covered by additional income induced by higher levels of human capital. The optimal amount of educational activities equalizes the marginal additional income to the marginal cost (see also Dustmann and Glitz, 2011).

As $t$ increases, the accumulation of educational output makes human capital increasing. But decreasing returns to human capital imply that, with a higher level of human capital and a shorter remaining lifetime, the future return to new human capital generated by education is lower (Chiswick and Miller 1994), so that the agent invests less in education. This effect is particularly strong if education is largely undertaken for productive purposes rather than as a pure leisure good (that is, for consumption purposes).

We also prove the existence of a limit trajectory: while all the trajectories below the limit are feasible there is no feasible one above it as investing in additional education does not generates utility gains. The existence of this limit trajectory implies that, if the initial level of human capital is high enough, the agent decides not to engage in education for two reasons. First, decreasing marginal returns to human capital imply that the marginal increase in future income generated by additional education is too low. Second, a higher level of human capital implies a higher marginal cost of time devoted to education, as this cost includes forgone earnings. For lower levels of human capital, the agent starts devoting some time to education, provided education is accessible and costs are not too high.

In the Appendix, we also analyze the impact of several factors that may influence the choice of the optimal trajectory. The first one, as emphasized above, is the initial level of human capital, $h_{0}$. We prove that time devoted to education is a decreasing function of $h_{0}$. The second one is the efficiency of education, measured by the parameter $a$. We prove that agents who have a higher efficiency in generating human capital from education ( $a$ being higher) devote more time to education. The third one is the fixed cost of education, $\varepsilon$. We find that a change in $\varepsilon$ has an ambiguous effect on time devoted to education. The fourth one is time availability, $\bar{\theta}$. We find that agents who have more time resources devote some of these extra time resources to education. Time availability might be highly different across gender and, in particular, when the presence of children constrains the time that can be devoted to labour participation. The last one is the rate of time preference, $\rho$. We find that agents who are more impatient ( $\rho$ being 
higher) choose to devote less time to education, as they value less future gains from the increase in human capital generated by education.

In the empirical exercise that follows we test these theoretical predictions and explicitly include explanatory and control variables that correspond, directly or indirectly, to the theoretical factors described above. However, some of these factors are not observable and, as they potentially differ across populations, may explain the observed difference between immigrants and natives sharing the same observable characteristics.

The main case is human capital. Even if an immigrant has the same observed level of education as a native, part of the education has been acquired in the origin country and is not fully transferable to the host country, so that the (effective) level of human capital in the host country is lower, leading to more time devoted to education. Unobservable differences in the rate of time preference may also matter, with a qualitatively similar effect. Generally, immigrants tend to discount the future less than natives, and are more likely to accept and trade-off temporary hardships against future gains (Goldbach and Schluter 2018; Nowotny 2014; Gibson and McKenzie 2011; Arcand and Mbaye 2013). ${ }^{5}$ Our model predicts that this lower discount of the future also leads to more time devoted to education.

There may also be unobservable differences in efficiency of education: immigrants are likely to face more difficulties generating human capital from education with an effect that is running counter the previous positive impacts (i.e. reducing the probability to engage in education) but, conditional on an immigrant engaging in learning activities, the time devoted to it might be higher. ${ }^{6}$ This is the case, for example, when immigrants, especially those coming from countries that have educational systems very different from the US, have to adapt to a new educational system that applies different teaching methods, evaluation systems and learning approaches.

A further difference relates to the time constraint. In this respect, the status of immigrant might have an ambiguous effect. One the one hand immigrants-by being less rooted in the host

\footnotetext{
${ }^{5}$ The hypothesis that immigrants are more tolerant toward risk and temporary hardships has long been emphasized in the migration literature. In fact, out-migration (in particular across borders) entails high initial up-front (sunk) costs in a highly risky environment with expected benefits that will materialize with a rather long time-lag (Gibson and McKenzie 2011). Hence, patient and risk-prone individuals are more likely to self-select in out-migration. Empirical evidence based on survey as well as experimental data confirm these hypothesis and shows that migrants are more risk-tolerant and also more patient - i.e. have a lower time preference - compared to natives (Nowotny 2014; Gibson and McKenzie 2011; Arcand and Mbaye 2013; Goldbach and Schluter, 2018).

${ }^{6}$ This hypothesis is consistent with the observation that immigrants from non-english speaking and/or developing countries (including highly skilled ones) are more likely to engage in educational activities upon arrival (see for instance Haley and Taengnoi 2011 on US) compared to other immigrants controlling for observable characteristics including formal education.
} 
society - might experience lower time-absorbing social obligations but, on the other hand, their time-use might be affected by more binding credit constraints or can be absorbed more by timeconsuming non-productive-activities such as commuting (see Hamermesh and Trejo 2013) or by time devoted to managing larger families.

\section{Data and methodology}

\subsection{Description of the data}

We use the American Time-use Survey (ATUS) for the years 2003-15 in our analysis ${ }^{7}$. Individuals surveyed in ATUS are selected randomly from households that participate in the Current Population Survey (CPS). The sample is representative of the population residing in the United States. Data is collected through one-day time diaries ${ }^{8}$, where participants list the time (in minutes) allocated to activities performed in the 24 hours prior to the survey. These activities are defined over a set of standardized categories (approximately 400). Finally, for each respondent, information on time-use can be matched with a wide array of demographic characteristics and labor market situation collected by the CPS. The dataset we use includes approximately 170 thousand individuals aged 15 years or more, where immigrants account for 14.5 percent of the total number.

Time-diary method has several advantages compared to other data collection methods (see Ribar 2012; and Juster, Ono, and Stafford 2003 for an overview). The most important one is accuracy that stems from the short recall period and the episodic format (must add up to 24 hours) which allows for consistency checks by the user. Barrett and Hamermesh (2019) argue that this type of data also reduces errors related to the different importance given to activities by survey respondents (see Bound, Brown, and Mathiowetz 2001). Conversely, two main disadvantages of the data are worth mentioning. The first limitation of the time-use data is highlighted by Juster, Ono, and Stafford (2003) who show that reporting on occasionally performed activities tend to be less reliable. However, in our study, this limitation is not an issue as most activities that belong to the education category are not occasional and are likely

\footnotetext{
${ }^{7}$ The ATUS data set is publicly available upon registration. We used the American Time-use Survey Extract Builder to extract the data (Hofferth, Flood, and Sobex 2017) https://www.atusdata.org/atus/

${ }^{8}$ ATUS diary days are assigned randomly and distributed across the days of the week, with 10 percent allocated to each day of the week and 25 percent allocated to Saturday and Sunday. This distribution is based on research showing that in weekends the allocation of time is different as compared to the rest of the working days (Horrigan and Hertz 2004).
} 
to have a well-defined time schedule. The second limitation is related to the high variability of time-diary data due to the one-day observation ${ }^{9}$. If interviewed on different days during the year, responses are likely to vary across days. One possible effect of the high variability is the reduction of the statistical power of the model, especially when estimations use a low number of observations (usually the second tier in our estimations). We show below that this drawback is unlikely to undermine our results.

Table 1 reports the descriptive statistics of the dependent variables (informal and formal education). All statistics are weighted to reflect the behavior of a representative individual in the US on a representative day.

Table 1 Participation rate and time spent in formal and informal education by immigrants, natives and second-generation.

\begin{tabular}{llcccc}
\hline & & \multicolumn{2}{c}{ IMMIGRANTS } & \multicolumn{2}{c}{ NATIVES } \\
\cline { 3 - 6 } & $\begin{array}{c}\text { Participation } \\
\text { rate } \%\end{array}$ & $\begin{array}{c}\text { Conditional } \\
\text { Mean } \\
\text { (minutes/day) }\end{array}$ & $\begin{array}{c}\text { Participation } \\
\text { rate } \%\end{array}$ & $\begin{array}{c}\text { Conditional } \\
\text { Mean } \\
\text { (minutes/day) }\end{array}$ \\
\hline Total & Informal education & 1.2 & 141 & 0.9 & 108 \\
& Formal education & 3.1 & 263 & 3.3 & 261 \\
\multirow{4}{*}{ Male } & Informal education & 1.4 & 128 & 1 & 107 \\
& Formal education & 3.2 & 255 & 3.4 & 250 \\
& Informal education & 1 & 170 & 0.7 & 111 \\
\hline Second & Formal education & 3.1 & 276 & 3 & 280 \\
generation & Informal education & 1.2 & 132 & & \\
\hline Notes: Statistics are weighted using the variable wt06 (ATUS methodology for 2006) & & & &
\end{tabular}

Notes: Statistics are weighted using the variable wt06 (ATUS methodology for 2006).

Informal education activities are performed more frequently by immigrants ( 1.2 percent) than by natives ( 0.9 percent) while there is not much difference for formal education. Conditional on participation, immigrants are also shown to spend more time in informal education than natives (141 minutes vs. 108 minutes) while, once again, there is not much difference for formal education. Female immigrants participate more in informal education but spend significantly less time in these activities as compared to male immigrants. Formal education activities and the time dedicated to them are more uniform across genders. Second-generation immigrants show a similar participation in informal education and the time spent in these activities is like that of immigrants, whereas the rate of participation in formal education is twice that of immigrants and of natives.

\footnotetext{
${ }^{9}$ The most notable differences are between weekdays and holidays for which we control using a dummy that distinguishes between weekdays and holidays.
} 
Table 1A in Appendix 1 shows that immigrants and natives are comparable in terms of gender, employment status and attainment of advanced degrees (degree and postgraduate).

Immigrants are of younger age, are more likely to be married and to have children than natives. They are also less likely to have obtained a high school diploma or equivalent than natives (50 percent and 64 percent, respectively). Summary statistics also show that the presence of individuals in the survey with less than elementary education is very low, among both immigrants and natives (1.06 percent). This feature reduces the likelihood of errors in reporting of activities from individuals ${ }^{10}$.

\subsection{Estimation strategy}

To test our hypothesis, we employ a double-hurdle (two tier) method proposed by Cragg (1971). This method is used to analyze differences in the allocation of time between natives and immigrants over broad classes of activities by Hamermesh and Trejo (2013). The double-hurdle method incorporates a probit model in the first tier that gives the probability that the observation has a positive value (extensive margin) and a truncated regression in the second tier (conditional intensive margin). As an alternative to a Tobit, this method allows for the possibility that different processes determine the two tiers, and hence the model could be estimated over two vectors of parameters. In terms of our analysis, the probit model $\left(1^{\text {st }}\right.$ tier) will test if immigrants and natives have a dissimilar probability to participate in formal and informal education, while the truncated model ( $2^{\text {nd }}$ tier), conditional on engaging in education, will test if immigrants participate more intensively than natives in such activities.

The specification of the baseline model is presented below:

$1^{\text {st }}$ tier: Probability of participation

$$
Y_{i s t}(0,1)=\alpha_{0}+\beta_{1} \text { ForeignBorn }_{i}+\boldsymbol{\beta}_{2} \boldsymbol{X}_{i}^{\prime}+\boldsymbol{\beta}_{3} \text { Holiday }_{i}+\boldsymbol{\varphi}_{i s}^{\prime}+\boldsymbol{\gamma}_{i t}^{\prime}+\varepsilon_{i s t}
$$

$2^{\text {nd }}$ tier: Intensity of participation

$$
E d u_{i s t}=\gamma_{0}+\delta_{1} \text { ForeignBorn }_{i}+\boldsymbol{\delta}_{2} \boldsymbol{X}_{i}^{\prime}+\boldsymbol{\delta}_{3} \text { Holiday }_{i}+\boldsymbol{\varphi}_{i s}^{\prime}+\boldsymbol{\gamma}_{i t}^{\prime}+\omega_{i s t}
$$

\subsubsection{Dependent variables}

We define formal education as all the non-work education activities such as taking classes and research and homework for a degree. Conversely, informal education includes all the

\footnotetext{
${ }^{10}$ Note that in order to minimize coding and classification errors, individuals describe the activities they perform using their own words. These activities are, therefore, classified into a set of standardized activities by ATUS staff.
} 
extracurricular activities that have a human capital component and classes carried out outside the formal educational system. This definition is similar to the definition used by Fahr (2005). Table 1B in Appendix 1 reports the list of activities included in the definitions of formal and informal education. Given the nature of the data generation process, we could not further disaggregate the informal education variable and distinguish between activities such as language courses or academic classes from other activities which besides having human-capital enhancing effects, can be considered as quasi-leisure activities ${ }^{11}$. Although further disaggregation of this variable would have potentially revealed some heterogeneous effects depending on the specific activity, our main idea is to consider all the activities - including those that have a strong leisure component - that generate at least potentially positive effects on the accumulation of human as well as social capital. In this respect, participation in a chess club may be considered as a human capital enhancing activity in a way similar to participation in an English language course. Both activities lead to accumulation of skills and improve cognitive abilities that might be useful in the labor market. In addition, both activities lead to social interactions that might have positive effects by increasing returns to other production factors or simply by increasing the chances of employability. More specifically, the dependent variables in the $1^{\text {st }}$ tier equation $\left(Y_{i s t}\right)$ is dichotomous and equals 1 if the respondent $i$ declares to have spent time (minutes $>0$ ) in formal (informal) education during the day the time-diary was recorded, and 0 otherwise. The dependent variables - included in $E d u_{i s t}{ }^{-}$in the $2^{\text {nd }}$ tier equation measure the time spent (in minutes) in formal or informal education by the respondent $i$ during the day the time-diary was recorded.

\subsubsection{Explanatory and control variables}

Our main explanatory variable is ForeignBorn ${ }_{i s t}$. It equals unity if the individual $i$, who resides in U.S. State $s$ in year $t$, was born abroad and 0 otherwise. Based on our theoretical framework, we expect that foreign-born persons might be more likely to allocate time to education for the following reasons (see section 2.2): i) partial transferability of human capital might imply that marginal returns to education are higher even controlling for educational attainment; ii) immigrants are generally more patient and discount the future relatively less than natives. Moreover, as immigrants might have a more restricted set of options for human capital enhancing activities, we expect them to rest more upon informal education.

\footnotetext{
${ }^{11}$ According to ATUS staff, after a time-diary is processed and codified into standardized categories the original recording is destroyed and hence not accessible to researchers.
} 
In both equations, the vector $\boldsymbol{X}_{i s t}^{\prime}$, includes individual level characteristics that, following our model, might condition the propensity to participate in educational activities and the intensity to perform these activities. The first characteristic of interest is the age of the respondent (Age) and its quadratic form (Age squared). Following our theoretical model that predicts that time devoted to education decreases along every trajectory, we expect age to have a negative effect on both the probability of participating in education and the intensity of this participation.

Our second characteristic of interest is educational attainment (Less than elementary, Elementary, Middle, Secondary, Degree, Postgraduate), which is our proxy for the initial level of human capital included in the theoretical framework. Following this framework, we expect that higher levels of formal education will be associated with lower incentives to invest in educational activities (see section 2.2), as a consequence of our assumption of decreasing returns related to these human capital enhancing activities.

A third group of characteristics encompasses gender (Female), marital status (Married), and whether the respondent has children in the following age groups: No children, children 0-2 years, children 3-5 years, children 6-12 years, children 13-17 years. These characteristics are highly correlated with time availability: homework rests more upon females than males, reducing time available for other activities; the presence of children also reduces time availability, again particularly for females. Then, in our theoretical framework, we expect working females and respondents with children to have less time available, leading to a lower probability of education and a lower intensity of participation

We include a set of dummies for the work status of the individual (Employed, Unemployed, Not in labor force) and seven dummies for the size of the area where the individual resides. Work status is also likely to influence time-constraints that might affect the willingness/ability to allocate time to informal education. For instance, we expect that time-constraints will be less binding for unemployed or individuals not in the labor force.

Last, it is important to acknowledge that, for matters of simplification, our theoretical model neglects the leisure value of education, which is likely to be positively related with educational level. Besides, formal and informal education might have a certain degree of complementarity. Both these aspects might offset the effects explicitly formalized in our theoretical framework. Moreover, in the baseline model the dummy Holiday indicates whether the diary day is a holiday ${ }^{12}$ while the vectors $\boldsymbol{\varphi}_{S}^{\prime}$ and $\boldsymbol{\gamma}_{S}^{\prime}$ refer to State fixed-effects and year fixed effects,

\footnotetext{
${ }^{12}$ Holidays include Sunday, New Year's Day, Easter, Memorial Day, $4^{\text {th }}$ of July, and Christmas.
} 
respectively. For the exact definition of the variables included in our empirical specification, we refer the reader to Table $1 \mathrm{C}$ in the Appendix 1.

\section{Empirical results}

\subsection{Baseline results}

Table 2 presents the results of the baseline model. Model 1 and model 2 ( $1^{\text {st }}$ tier), estimated over the entire sample, show that the probability to participate in formal as well as informal education activities is 0.4 percent higher for the foreign-born than it is for natives. Conditional on participation ( $2^{\text {nd }}$ tier), the foreign-born spend, on average, 62 minutes (or 57 percent) ${ }^{13}$ more in informal education activities and 11 (or 4\%) more in formal education than similar US-born people do in the diary day; then, if the impact of being foreign born is similar for formal and informal education, the impact on time spent in much higher for informal education. In this model, we control for a wide range of individual level characteristics, which explain a good part of the heterogeneity in the time spent in informal education across individuals. Consistent with our theoretical prediction, we find that younger individuals and females are more likely to participate in both formal and informal education activities. However, the intensity of time spent in such activities is higher for younger individuals, and lower for females than for male. Moreover, the negative impact of age on the participation to educational activities is much stronger for formal education than for informal education.

As expected, individuals with young children are less likely to engage in educational activities, whether they are formal or informal, than those who have no children, and when they engage, the time spent in these activities is significantly lower. Informal education activities are performed more frequently but less intensively during holidays. The labor market status of individuals determines the time spent in informal education activities. Unemployed and inactive individuals are more likely to engage in both formal and informal education activities than employed individuals, and the time spent in these activities is evidently higher. Unemployed individuals might engage more intensively in educational activities to acquire skills and competences that grant a (future) labor-market return.

\footnotetext{
${ }^{13}$ Assessed on the average time spent in informal education by natives.
} 
Table 2 Time spent in informal and formal education: immigrants versus natives (baseline estimations on the full sample)

\begin{tabular}{|c|c|c|c|c|}
\hline \multirow[b]{2}{*}{ VARIABLES } & \multicolumn{2}{|c|}{$\begin{array}{c}\text { Model } 1 \\
\text { INFORMAL EDUCATION }\end{array}$} & \multicolumn{2}{|c|}{$\begin{array}{c}\text { Model } 2 \\
\text { FORMAL EDUCATION }\end{array}$} \\
\hline & Tier1 & Tier2 & Tier1 & Tier2 \\
\hline Foreign Born & $0.0044 * * *$ & $62.04 * * *$ & $0.0041 * *$ & $11.02 *$ \\
\hline Age & $-0.0006 * * *$ & $9.376 * *$ & $-0.0069 * * *$ & $-7.806^{* * *}$ \\
\hline $\mathrm{Age}^{2}$ & $4 \mathrm{e}-06 * * *$ & $-0.121 * * *$ & $4 \mathrm{e}-05 * * *$ & $0.0815^{* * *}$ \\
\hline Female & $0.00393 * * *$ & $-36.10^{*}$ & $0.0105^{* * *}$ & $-17.11 * * *$ \\
\hline Married & 0.000719 & 7.330 & $-0.0112 * * *$ & -8.120 \\
\hline Children 0-2 & $-0.0067 * * *$ & $-102.9 * *$ & $-0.0291 * * *$ & $-31.47 *$ \\
\hline Children 3-5 & $-0.003 * * *$ & $-127.5 * * *$ & $-0.0144 * * *$ & $-44.61 * * *$ \\
\hline Children 6-12 & $-0.0023 * * *$ & -12.58 & $-0.0054 * * *$ & $-39.93 * * *$ \\
\hline Children 13-17 & 0.000124 & -16.56 & $0.00812^{* * *}$ & 22.39 \\
\hline Less than elementary & $0.0100^{*}$ & $-203.8^{*}$ & -0.0016 & $246.4 * * *$ \\
\hline Middle school & $0.0102 * *$ & 80.67 & 0.0142 & $136.5^{*}$ \\
\hline Secondary & $0.00989 * *$ & 111.3 & $0.0354 * * *$ & $144.5^{* *}$ \\
\hline Degree & $0.0143 * * *$ & 139.7 & $0.0407 * * *$ & $186.5 * * *$ \\
\hline Postgraduate & $0.0172 * * *$ & 118.7 & $0.0407 * * *$ & $213.7 * * *$ \\
\hline Holiday & $0.00344 * * *$ & $-105.5 * * *$ & $-0.0123 * * *$ & $-224.8 * * *$ \\
\hline Unemployed & $0.0046^{* * *}$ & $68.69 * *$ & $0.0167 * * *$ & $81.47 * * *$ \\
\hline Not in labor force & $0.00508 * * *$ & $79.98 * * *$ & $0.0260 * * *$ & $110.6 * * *$ \\
\hline Constant & & $-308.5^{*}$ & & $218.5 * * *$ \\
\hline Sigma & & $191.1 * * *$ & & $210.6^{* * *}$ \\
\hline Observations & 169,724 & 1665 & 169,724 & 8145 \\
\hline
\end{tabular}

Besides, these individuals are likely to be less time constrained than employed individuals are, as highlighted in our model. Finally, the educational attainment is positively associated with the likelihood to engage in informal education activities. According to Fahr (2005), highly educated people have a higher opportunity cost of their non-market-time and a preference for educational leisure. Another possible explanation is the higher complementarity - both in production and consumption - between formal and informal education.

In Table 3, we exclude unemployed and inactive individuals from the sample - and focus on employed individuals only - as these two groups substantially differ in terms of time constraints as well as in terms of the opportunity cost of allocating time to non-market activities $^{14}$. The results are similar to the results for the full sample. However, the marginal impact of being a foreign born is now higher for formal education that for informal education

\footnotetext{
${ }^{14}$ Income dummies are used to control for the opportunity cost of engaging in non-market-activities.
} 
and the marginal impact on time devoted to educational activities is very high for informal education. This result could be partially explained by the well-defined time schedule of curricular activities.

Table 3 Time spent in informal and formal education: immigrants versus natives (baseline estimations on the sample of employed only)

\begin{tabular}{|c|c|c|c|c|}
\hline \multirow{2}{*}{ VARIABLES } & \multicolumn{2}{|c|}{$\begin{array}{c}\text { Model } 1 \\
\text { INFORMAL EDUCATION }\end{array}$} & \multicolumn{2}{|c|}{$\begin{array}{c}\text { Model } 2 \\
\text { FORMAL EDUCATION }\end{array}$} \\
\hline & Tier1 & Tier2 & Tier1 & Tier2 \\
\hline Foreign Born & $0.0032 * * *$ & $86.56 * *$ & $0.0059 * * *$ & 5.388 \\
\hline Age & $-0.0007 * * *$ & 6.475 & $-0.0076^{* * *}$ & $-21.44 * * *$ \\
\hline $\mathrm{Age}^{2}$ & $7 \mathrm{e}-06 * * *$ & -0.108 & $6 \mathrm{e}-05 * * *$ & $0.265^{* * *}$ \\
\hline Female & $0.0027 * * *$ & -37.15 & $0.0130 * * *$ & $-23.73 * *$ \\
\hline Married & 0.000253 & 9.986 & $-0.0086^{* * *}$ & 2.493 \\
\hline Children 0-2 & $-0.0037 * * *$ & $-153.1 * *$ & $-0.0188 * * *$ & -0.473 \\
\hline Children 3-5 & $-0.00214 *$ & $-162.2 * * *$ & $-0.009 * * *$ & $-32.93 *$ \\
\hline Children 6-12 & -0.00141 & -35.43 & $-0.00364 * *$ & $-33.71 * *$ \\
\hline Children 13-17 & 0.000672 & 10.27 & $0.0049 * * *$ & $54.88 * * *$ \\
\hline Less than elementary & 0 & 0 & -0.0039 & $421.3^{* *}$ \\
\hline Middle school & 0.00353 & $325.4^{*}$ & -0.0106 & $306.2 * *$ \\
\hline Secondary & $-4 \mathrm{e}-05$ & $337.9 *$ & 0.0218 & 260.1 \\
\hline Degree & 0.0038 & $396.8^{* *}$ & $0.0235^{*}$ & $309.8 * *$ \\
\hline Postgraduate & 0.0057 & $415.3^{* *}$ & 0.0193 & $320.8 * *$ \\
\hline Holiday & $0.0034 * * *$ & -47.25 & $-0.0061 * * *$ & $-149.4 * * *$ \\
\hline $\begin{array}{l}\text { Household income } \\
\text { dummies }\end{array}$ & YES & YES & YES & YES \\
\hline Constant & & $-593.5^{*}$ & & $300.5^{*}$ \\
\hline Sigma & & $191.9 * * *$ & & $210.7 * * *$ \\
\hline Observations & 98,118 & 768 & 98,216 & 3475 \\
\hline
\end{tabular}

Dependent variables: $1^{\text {st }}$ Tier is informal or formal education $(0,1) ; 2^{\text {nd }}$ Tier is time spent in informal or formal education. Reference categories are: No children; Elementary; Employed. Area size dummies, state and year fixed effects are used in all models. For the $1^{\text {st }}$ Tier, marginal effects at means of all independent variables are reported. Errors are clustered at the state level. $* * * \mathrm{p}<0.01, * * \mathrm{p}<0.05, * \mathrm{p}<0.1$

An additional driver of the higher propensity and intensity of investment in informal education activities by foreign workers can be due to reduced access to on-the-job training. As training is paid by the firm, more informal education undertaken by foreign born might be (at least partly) the results of firms transferring a higher share of these costs to immigrant workers or/and a higher concentration of immigrants' workers in sectors where a higher proportion of these costs is transferred to workers. ${ }^{15}$

${ }^{15}$ In order to test the relevance of this 'discrimination' channel vis-à-vis other competing explanations we would need detailed information concerning on-the-job training activities by immigrants as well as natives. Unfortunately, these information are not available in our dataset. Restricting the analysis to employed individuals 
Our theoretical framework and the results of the analysis in Table 2 suggest that one reason why immigrants spend more time in education is the higher returns they obtain from these activities. Consistent with the theoretical prediction, the economic incentive to engage in human capital enhancing activities is higher for individuals that could reap the benefits for longer time. For instance, those who are close to retirement could have a lower incentive to invest in informal education than individuals at an early stage of their working life.

Table 4 Residual working life and time-use in formal and informal education

\begin{tabular}{|c|c|c|c|c|}
\hline \multirow[b]{2}{*}{ VARIABLES } & \multicolumn{2}{|c|}{$\begin{array}{c}\text { Model } 1 \\
\text { INFORMAL EDUCATION }\end{array}$} & \multicolumn{2}{|c|}{$\begin{array}{cl} & \text { Model } 2 \\
\text { FORMAL EDUCATION }\end{array}$} \\
\hline & Tier1 & Tier2 & Tier1 & Tier2 \\
\hline Foreign born $<=45$ years & $0.0046 * * *$ & $62.98 * *$ & $0.0017 * *$ & $20.38 * *$ \\
\hline Foreign born $>45$ years & $0.002 * * *$ & 21.87 & $0.008 * * *$ & $63.62 *$ \\
\hline Constant & & -139.4 & & -100.81 \\
\hline Sigma & & $181.5 * * *$ & & $243.2 * * *$ \\
\hline Observations & 162,236 & 1449 & 162,236 & 4673 \\
\hline
\end{tabular}

Dependent variables: $1^{\text {st }}$ Tier is informal or formal education $(0,1) ; 2^{\text {nd }}$ Tier is time spent in informal or formal education. Individuals over 17 years old are considered. This table includes all control variables as in Table 2. For the $1^{\text {st }}$ Tier, marginal effects at means of all independent variables are reported. Errors are clustered at the state level. $* * * \mathrm{p}<0.01, * * \mathrm{p}<0.05, * \mathrm{p}<0.1$

In Table 4, we test the validity of this argument by including in the baseline model an interaction between the dummy for foreign-born individuals who are 45 years of age or younger and a dummy for foreign-born individuals who are older than 45 years of age ${ }^{16}$. In Model 1, which includes the results of estimations having informal education as a dependent variable, foreign-born individuals who are 45 years of age or younger are twice more likely to engage in informal education activities (compared to natives) than foreign-born individuals who are older than 45 years of age. The results show the same tendency when the conditional amount of time spent in such activities is considered. A different picture emerges when looking at formal education (Model 2). Older immigrants are more inclined to invest time in formal education than younger immigrants (compared to natives), and they also spend significantly more time in these activities.

and including sectoral dummies (in order to account for self-selection of immigrants in sectors with higher degree of discrimination) as well as workers' characteristics such as gender, age, education seems to suggest that the higher propensity to engage in informal educations goes beyond the discrimination channel. We are grateful to an anonymous referee for suggesting this possible interpretation.

${ }^{16}$ Only individuals with more than 17 years of age are considered in the estimations. The results hold if the threshold age is 40 years and when only individuals within $17-65$ years of age are considered. 
As argued above, informal education activities could represent a fundamental source of knowledge and country-specific human (and social) capital for immigrants. For example, attending language club activities or taking art and craft courses may boost host countryspecific skills/knowledge and language proficiency. It is highly likely that these activities will be particularly rewarding for immigrants originating from countries where English is not the official language. We test this hypothesis and report the results in Table 5 where we consider the official language of immigrants home countries (we follow the definition of Bleakley and Chin 2004). We find that foreign born from non-English speaking countries have the strongest propensity to invest in informal education (both at the extensive and intensive margins). Interestingly, the probability of engaging in formal education is lower compared to immigrants from countries where English is the official language or a widely spoken one. The latter result suggests higher cost of entry for these immigrants in formal education.

Table 5. Time spent in education and home country language.

\begin{tabular}{lcccc}
\hline & \multicolumn{2}{c}{ Model 1 } & \multicolumn{2}{c}{ Model 2 } \\
& INFORMAL EDUCATION & FORMAL EDUCATION \\
VARIABLES & Tier 1 & Tier2 & Tier 2 & Tier 1 \\
\hline & & & & \\
Non English speaking & $0.00407^{* * *}$ & $73.21^{* * *}$ & 0.000591 & $16.70^{* * *}$ \\
English speaking & $0.00233^{* *}$ & 3.154 & $0.00803^{* * *}$ & -16.13 \\
English official & $-4.53 \mathrm{e}-06$ & -3.324 & $0.00744^{* * *}$ & -7.012 \\
\hline Constant & & $-314.9^{*}$ & & $214.7^{* *}$ \\
Sigma & & $190.6^{* * *}$ & & $210.6^{* * *}$ \\
Observations & 169,724 & 1665 & 169,724 & 8145 \\
\hline
\end{tabular}

Dependent variables: 1 st Tier is informal and formal education $(0,1)$; 2nd Tier is time spent in informal and formal education. This table includes all control variables as in Table 2. Reference categories are: No children; Primary; Employed; native-born. Area size dummies, state and year fixed effects are used in all models. For the 1st Tier, marginal effects at means are reported. Errors are clustered at the state level. $* * * \mathrm{p}<0.01, * * \mathrm{p}<0.05, * \mathrm{p}<0.1$

Jointly, these results suggest that for foreign born from non-English speaking countries informal education might be a fundamental (and maybe the only) channel for acquiring the required human capital that would allow socio-economic integration.

It is also reasonable to expect that the longer the immigrants reside in the host country, the higher is the level of country-specific human capital accumulated and the lower will be the difference with the human capital of natives. This argument is in line with the assimilation theory suggesting convergence in the use of time between immigrants and natives. To test the validity of this argument, we replace the foreign-born dummy of the baseline model by a set of dummy variables categorizing the time since migration of individuals and a dummy for second- 
generation Americans ${ }^{17}$. The results are displayed in Table 6. They are quite similar for formal and informal education. In line with our predictions, the propensity to engage in both formal and informal education is higher for recent immigrants and decreases steadily with the time spent in the US. Immigrants residing in the US for less than 6 years are almost 8 times more likely to engage in educational activities than immigrants who have been in the US for more than 20 years. However, the results also show that the amount of time spent in educational activities does not follow a clear decreasing pattern when time since immigration increases.

Table 6 Time since migration and time-use in informal and formal education

\begin{tabular}{llcll}
\hline & \multicolumn{2}{c}{ Model 1 } & \multicolumn{2}{c}{ Model 2 } \\
& INFORMAL EDUCATION & \multicolumn{2}{c}{ FORMAL EDUCATION } \\
VARIABLES & Tier1 & Tier2 & Tier1 & Tier2 \\
\hline Second generation & $0.0016^{* *}$ & 12.43 & $0.002^{* *}$ & $37.61^{* * *}$ \\
Year since immigration: $<6$ & $0.0084^{* * *}$ & $101.1^{* *}$ & $0.0082^{* * *}$ & $52.79 * * *$ \\
Year since immigration: $6-10$ & $0.0047^{* * *}$ & -9.040 & $0.0043^{* * *}$ & $56.10^{* *}$ \\
Year since immigration: $11-20$ & $0.0048^{* * *}$ & $71.00^{* *}$ & $0.0017^{*}$ & 24.19 \\
Year since immigration: $>20$ & $0.001^{*}$ & 44.20 & 0.0005 & $40.43^{* *}$ \\
\hline Constant & \multicolumn{5}{c}{-123.5} & 6.754 \\
Sigma & 162,236 & $144.0^{* * *}$ & & $256.0^{* * *}$ \\
Observations & & 1449 & 162,236 & 4673 \\
\hline
\end{tabular}

Dependent variables: $1^{\text {st }}$ Tier is informal or formal education $(0,1) ; 2^{\text {nd }}$ Tier is time spent in informal or formal education. Individuals over 17 years old are considered. This table includes all control variables as in Table 2 . For the $1^{\text {st }}$ Tier, marginal effects at means of all independent variables are reported. Errors are clustered at the state level. ${ }^{* * *} \mathrm{p}<0.01,{ }^{* *} \mathrm{p}<0.05, *$ $\mathrm{p}<0.1$

Second-generation Americans look like natives in terms of time spent in informal education and devote more time to formal education. Their propensity to engage in these activities is higher than that of natives but does not differ much from that of immigrants who have been in the US for more than 20 years. Overall, the results suggest that a slow process of assimilation with natives is ongoing and that this process is not fully completed for the second-generation immigrants.

\footnotetext{
${ }^{17}$ Both variables are used by Hamermesh and Trejo (2013) to measure the process of assimilation of immigrants in terms of time-used in purchasing, education and work activities. Their definition of education includes both formal and informal education.
} 


\subsection{Formal and informal education: The complementarity issue}

So far, in our analysis, we have excluded the possibility that the time spent in formal education and informal education activities might complement each other. In many cases, classes for a degree could be complemented with additional extracurricular classes or club activities aimed at enhancing the knowledge of a topic or gaining new skills. However, individuals might combine investment in formal and informal education differently. For example, individuals that have already completed their formal educational track may decide to further invest in informal education as a way to avoid skills and human capital depreciation or to update their skills and competences. Evidently, investments in informal education complement previous investments in formal education and occur when individuals have already completed the formal educational track. This latter typology of complementarity has a sequential rather than a contemporary nature ${ }^{18}$.

When individuals' choices over these two activities are simultaneous (that is, taken in the same period under analysis), the estimates presented above are likely to be biased if formal (resp. informal) education is not considered explicitly in the analysis of informal (resp. formal) education ${ }^{19}$. One way to deal with this issue is to restrict the sample to only those individuals that are not enrolled in formal education, for which the risk of simultaneity is quite low or even absent. The ATUS data has detailed information on whether the respondent was enrolled in school, high school or university in the week preceding the survey. We use this information to identify all individuals that declared to be enrolled in the formal educational system and exclude them from the estimations ${ }^{20}$. In Table 7, we investigate the presence of simultaneity and its effect on the baseline results. In Model 1, where we use the entire sample, we insert a dummy for individuals enrolled in formal education (In education) and its interaction with

\footnotetext{
${ }^{18}$ We exclude here the possibility that informal education could be performed before enrolling in formal education (for example, high school or university) and could determine further formal education. In any case, this circumstance and sequential complementarity in general does not invalidate the analysis as long as formal and informal education are not performed simultaneously. We control for sequential complementarity by using educational attainment dummies as in Fahr (2005).

${ }^{19}$ If time devoted to formal and informal education are simultaneously decided, then formal education is a crucial determinant of informal education. Hence, it must be explicitly controlled for in the estimations in order to avoid serious omitted variables bias. The fact that formal education is endogenous prevents its use in the econometric model.

${ }^{20}$ Individuals in formal education is only 10 percent of the sample. Note that for those who declare that they are not enrolled, we know their highest educational degree. Hence, we control for their level of educational attainment in the estimations.
} 
foreign-born (Foreign-born*In education). The results of Model 1 are informative in several ways: (i) the positive and significant coefficient of In education suggests the presence of simultaneity (that is, enrolled individuals are more likely to engage in informal education); (ii) the positive and significant coefficient of the interaction indicates that simultaneity could be higher for enrolled immigrants; (iii) the positive and highly significant coefficient of the dummy Foreign-born indicates that, even after controlling for formal education, immigrants are still more likely to engage in informal education, and conditional on participation, they spend more time in these activities (coefficient of Foreign-born in tier 2$)^{21}$.

Table 7 Informal and formal education of immigrants: substitutes or complements?

\begin{tabular}{|c|c|c|c|c|c|c|}
\hline \multirow[b]{2}{*}{ VARIABLES } & \multicolumn{2}{|c|}{$\begin{array}{c}\text { Model } 1 \\
\text { Full sample }\end{array}$} & \multicolumn{2}{|c|}{$\begin{array}{c}\text { Model } 2 \\
\text { Not in education }\end{array}$} & \multicolumn{2}{|c|}{$\begin{array}{c}\text { Model } 3 \\
\text { Not in education }\end{array}$} \\
\hline & Tier1 & Tier2 & Tier1 & Tier2 & Tier1 & Tier2 \\
\hline Foreign born & $0.003 * * *$ & $50.25 * *$ & $0.0028 * * *$ & $46.67 * *$ & & \\
\hline In education & $0.0058 * * *$ & -31.68 & & & & \\
\hline $\begin{array}{l}\text { Foreign born* In } \\
\text { Education }\end{array}$ & $0.002 * *$ & 43.94 & & & & \\
\hline Foreign born $<=45$ years & & & & & $0.0041 * * *$ & $55.74 * *$ \\
\hline$\underline{\text { Foreign born }>\text { years }}$ & & & & & $0.0016^{* * *}$ & 24.77 \\
\hline Constant & & $-260.4 *$ & & 4.935 & & 7.032 \\
\hline Sigma & & $190.8 * * *$ & & $172.9 * * *$ & & $170.6 * * *$ \\
\hline Observations & 169,724 & 1665 & 153,090 & 1279 & 151,912 & 1254 \\
\hline
\end{tabular}

Dependent variables: $1^{\text {st }}$ Tier is informal education $(0,1) ; 2^{\text {nd }}$ Tier is time spent in informal education. This table includes all control variables as in Table 2. In Model 3, only individuals over 17 years old are considered. For the $1^{\text {st }}$ Tier, marginal effects at means of all independent variables are reported. Errors are clustered at the state level. *** $\mathrm{p}<0.01, * * \mathrm{p}<0.05 *$, $\mathrm{p}<0.1$

To address the simultaneity issue, in Model 2 and Model 3 we include in the sample only individuals that are not enrolled in the formal educational system. The results of these estimations certify the results obtained on the whole sample of individuals and presented above in Table 2 and Table 4.

A further robustness check on the issue of potential simultaneity is reported in Table 7 where we estimate the baseline model separately for individuals that spend a positive amount of time in formal education (Model 1) and those who spend no time in formal education in the diary day (Model 2). In the former specification (that is, when simultaneity is present), the probability to engage in informal education is not significantly different for foreign born compared to natives. On the contrary, in Model 2-where simultaneity is less likely—results confirm what

\footnotetext{
${ }^{21}$ As stated in footnote (15), due to endogeneity, these relationships could not be interpreted as causal.
} 
was previously found in the baseline estimations presented above. Overall, the tests presented in this section confirm that our baseline results are not significantly affected by simultaneity.

Table 7 Informal and formal education for immigrants: substitute or complements?

\begin{tabular}{lcccc}
\hline & \multicolumn{2}{c}{ Model 1 } & \multicolumn{2}{c}{ Model 2 } \\
\hline VARIABLES & \multicolumn{2}{c}{ Time spent in formal edu>0 } & \multicolumn{2}{c}{ Time spent in formal edu=0 } \\
Tier1 & \multicolumn{2}{c}{ Tier2 } & Tier2 \\
\hline Foreign Born & 0.0043 & 17.27 & $0.0036^{* * * *}$ & $56.70^{* * *}$ \\
& & & & -128.2 \\
Constant & & 312.1 & & $186.3^{* * *}$ \\
Sigma & $106.5^{* * *}$ & & 1470 \\
Observations & 8,142 & 195 & 161,579 & 1470 \\
\hline
\end{tabular}

Dependent variables: $1^{\text {st }}$ Tier is informal education $(0,1) ; 2^{\text {nd }}$ Tier is time spent in informal education. This table includes all control variables as in Table 2. State fixed effects are not included in model 1 because the model does not converge. For the $1^{\text {st }}$ Tier, marginal effects at means of all independent variables are reported. Errors are clustered at the state level. $* * * \mathrm{p}<0.01, * * \mathrm{p}<0.05, * \mathrm{p}<0.1$

\section{Discussion and concluding remarks}

The accumulation of human capital in a society is fundamental for boosting growth, and more generally, the well-being of citizens. When this investment is carried out by immigrants there is an additional gain for the community at large as human capital speeds up the process of socio-economic integration.

In this paper, we study the allocation of time to informal as well as formal learning and education by immigrants and natives. We have focused our attention on informal education, a crucial channel (often the only available one) of human capital enhancement for immigrants. A theoretical framework allows us to generate hypotheses about the factors that drive individuals' incentives to invest in informal education, and to discuss how immigrants may diverge from natives with respect to some of these drivers. Our empirical findings, in line with our theoretical predictions, show that foreign-born individuals invest more than natives in educational activities, formal as well as informal. The probability of engaging in training and extra-curricular formative activities is higher for foreign-born people than for natives, and the time devoted to these activities, conditional on engaging in it, is longer. We show that the main drivers are economic incentives mostly in the early phase of working life, as differences tends to disappear over time, and in particular, when the residual working time is shortened. We also show that differences between the foreign-born and natives are generally larger in informal 
education than in formal education. As we are focusing on adults that have already made their decision over formal education when young, these findings show that informal education is fundamental in the process of investing in host-country specific human (and social) capital. Interestingly, the differences between natives and immigrants persist across generations. We find that second-generation immigrants tend to allocate more time to both informal and formal educational activities and that a slow process of assimilation with natives is ongoing.

Given the potential importance of informal education for immigrants' integration in the host economy and society, it would be interesting to explore additional dimensions that might facilitate or inhibit time allocated to these activities. Immigrants from different origin countries or living in different areas (such as more or less ethnically segregated ones) might have different propensities to invest in informal education. Analysis on other destination countries might also deliver interesting information that relates to the context in which migration takes place and the policies that govern the phenomena. More data on time-use in different countries are becoming available and more immigrants are being included in these data collection efforts. These interesting questions are left for future research.

\section{References}

Arcand, J., Mbaye, L., (2013), Braving the Waves: The Role of Time and Risk Preferences in Illegal Migration from Senegal, 7517 CERDI Working Paper.

Barrett, Garry, and Daniel, S. Hamermesh. 2019. "Labor Supply Elasticities Overcoming Nonclassical Measurement Error Using more Accurate Hours Data.” J. Human. Res. 54 (1): $255-265$.

Becker, Garry. S. 1965. “A Theory of the Allocation of Time.” Econ. J. 75 (299): 493 - 517.

Bleakley Hoyt, and Aimee Chin. 2004. "Language Skills and Earnings: Evidence from Childhood Immigrants" Rev. Econ. Stat. 86 (2): 481- 496

Bound, John, Charles, Brown, and Nancy Mathiowetz. 2001. "Measurement Error in Survey Data." In Handbook of Econometrics 5, edited by James Heckman and Edward Leamer. Amsterdam: Elsevier.

Borjas, George J. 2015. "The Slowdown in the Economic Assimilation of Immigrants: Aging and cohort Effects Revisited Again”, J. Human Cap. 9 (4): 483 - 517. 
Caparrós, Ruiz Antonio. 2017. “Adolescents' Time-use in Spain: Does the Parental Human Capital Matter?" Child Indicators Research. 10 (1): 81 - 99.

Chiswick, Barry R. 1978. "The Effect of Americanization on the Earnings of Foreign-Born Men.” J. Pol. Econ. 86 (5): 897-921.

Chiswick, Barry R and Paul W. Miller. 1994. "The Determinants of Post-Immigration Investments

in Education", Econ. Edu. Rev., 13(2): 163 - 177.

Chiswick, Barry R and Paul W. Miller. 2008. "Why is the Payoff of Schooling smaller for Immigrants? Lab. Econ., 15: 1317 - 1340

Chiswick, Barry R. and Paul W. Miller. 2012. "Negative and Positive Assimilation, Skill Transferability, and Linguistic Distance”. J. Human Cap. 9(1): 35 - 55.

Coleman, James, S. 1988. "Social Capital in the Creation of Human Capital." American J. Sociology. 94: 95 - 120.

Cragg, G. John. 1971. "Some Statistical Models for Limited Dependent Variables with Application to the Demand for Durable Goods." Econometrica 39 (5): 829 - 844.

Dustmann, Christian, and Albrecht Glitz. 2011. Migration and Education, Handbook of the Economics of Education, 4: 327 - 439.

Fahr, Rene. 2005. "Loafing or learning? - The Demand for Informal Education.” European Econ. Rev, 49: 75 - 98 .

Gibson, J., McKenzie, D., 2011. The microeconomic determinants of emigration and return migration of the best and brightest: evidence from the Pacific, J. Dev. Econ. 95, 18-29.

Goldbach, Carina, Schluter Achim (2018), Risk Aversion, time preferences, and out-migration. Experimental evidence from Ghana and Indonesia, Journal of Economic Behavior and Organization, 150: 132-148.

Green, Colin, Parvinder, Kler, and Gareth, Leeves. 2007. "Immigrant Overeducation: Evidence from Recent Arrivals to Australia”, Econ. Edu. Rev., 26: 420-432

Haley, M. Ryan, Taengnoi Sarinda (2011), The skill transferability of high-skilled US immigrants, Applied Economics Letters, 18:633-636.

Hamermesh, S. Daniel, and Gerard, A. Pfann. 2005. “Time-use Data in Economics.” European Econ. Rev. 49: 1 - 7.

Hamermesh, S. Daniel, and Stephan, J. Trejo. 2013. "How do Immigrants Spend their Time? The Process of Assimilation.” J. Pop. Econ. 26: 507-530. 
Hofferth, S. L., Flood, S.M., Sobek, M. 2017. American Time-use Survey Data Extract Builder: Version 2.6 [dataset]. College Park, MD: University of Maryland and Minneapolis, MN: University of Minnesota. http://doi.org/10.18128/D060.v2.7

Horrigan, Micheal, and Diane, Herz. 2004. "Planning, Designing and Executing the BLS American Time-use Survey.” Monthly Labor Review 127 (10): 3 - 19.

Juster, F. Thomas, Ono, Hiromi, and Frank P. Stafford. 2003. "An Assessment of Alternative Measures of Time-use.” Sociological Methodology, 33 (1): 19 - 54.

Mattoo, Aaditya, Ileana C. Neagu, and Çağlar Özden. 2008. "Brain Waste? Educated Immigrants in the US Labor Market, J. Dev. Econ., 87: 255 - 269

Nowotny, Klaus (2014), Cross-border commuting and migration intentions: the roles of risk aversion and time preference, Contemporary Economics, University of Economics and Human Sciences in Warsaw., vol. 8(2), June

OECD. 2014. "Skills Beyond School: Synthesis Report." OECD Reviews of Vocational Training: OECD Publishing. $\quad$ www.oecd-ilibrary.org/education/skills-beyondschool_9789264214682-en

Ribar, C. David. 2012. “Immigrants' Time-use: A Survey of Methods and Evidence.” In International Handbook on the Economics of Migration, edited by Amelie F. Constant and Klaus F. Zimmermann: Edward Elgar Publishing.

Zaiceva, Anzelika, and Klaus, F. Zimmermann. 2014. "Children, Kitchen, Church: Does Ethnicity Matter?" Rev. Econ. Household 12 (1): 83 - 10 


\section{Appendix 1}

Table 1A. Descriptive statistics of variables used in the estimation

\begin{tabular}{|c|c|c|c|c|}
\hline \multirow[b]{2}{*}{ VARIABLES } & \multicolumn{2}{|c|}{ Immigrants } & \multicolumn{2}{|l|}{ Natives } \\
\hline & Mean & St. Error & Mean & St. Error \\
\hline Age & 46.4 & 0.12 & 48.7 & 0.054 \\
\hline Female & 0.61 & 0.003 & 0.61 & 0.001 \\
\hline Married & 0.53 & 0.004 & 0.42 & 0.001 \\
\hline No children & 0.51 & 0.004 & 0.60 & 0.001 \\
\hline Children of age $0-2$ & 0.13 & 0.002 & 0.1 & 0.001 \\
\hline Children of age $3-5$ & 0.16 & 0.003 & 0.12 & 0.001 \\
\hline Children of age 6-12 & 0.29 & 0.004 & 0.24 & 0.001 \\
\hline Children of age $13-17$ & 0.16 & 0.003 & 0.13 & 0.001 \\
\hline Less than elementary & 0.01 & 0.001 & 0.0006 & 0.000 \\
\hline Elementary & 0.036 & 0.001 & 0.002 & 0.000 \\
\hline Middle school & 0.12 & 0.002 & 0.025 & 0.000 \\
\hline Secondary & 0.50 & 0.004 & 0.64 & 0.001 \\
\hline Degree & 0.187 & 0.003 & 0.21 & 0.001 \\
\hline Postgraduate & 0.14 & 0.003 & 0.12 & 0.001 \\
\hline Employed & 0.63 & 0.004 & 0.62 & 0.001 \\
\hline Unemployed & 0.05 & 0.002 & 0.042 & 0.000 \\
\hline Not in labor force & 0.32 & 0.004 & 0.33 & 0.001 \\
\hline Observations & & 865 & & 45.977 \\
\hline
\end{tabular}

Source: ATUS data (2003-15) 
Table 1B Definitions of informal and formal education

\section{INFORMAL EDUCATION}

1. Extracurricular club activities (category activity examples)

\section{Attending:}

American Field Service activities, including

meetings;

Key Club activities, including meetings

Language club activities

Math club activities

National Honor Society activities

Science club activities

\section{Taking class for personal interest (category activity examples)}

\section{Attending:}

Sunday school

Dance class (personal interest)

Prenatal/childcare classes (personal

interest)

Taking:

Car maintenance/repair class

Cooking class

Financial planning class

Massage class

Pottery class

Retirement planning seminar

Sewing class

Wine appreciation class

Academic class

Art, craft, hobby, recreational course
Talking:

To classmates

To teacher
Participating and practicing:

Academic club activities, including

meetings

Chess club activities, including meetings

Debate club competition

3. Research or homework for class for personal interest (category of activities)

Attending study group

Listening to language $\mathrm{CD}$

Organizing notes

Driver's education

Driving lessons

Music/voice lessons

On-line course

Parenting class

Personal development classes

Photography class

Self-defense class

Cardiopulmonary Resuscitation (CPR), first aid class

\section{Other activities for personal interest (category of activities)}

Preparing and studying for: SAT; GMAT; GRE; LSAT; CPA exam; English for personal interest (2015)

\section{FORMAL EDUCATION}

1. Taking class for degree, certification, or licensure

Attending (seminar, class, practicum/internship)

Taking exams

Auditing a course

Listening to a lecture

Taking on-line course

Talking to teacher

Taking a field trip

\section{Research or homework for class (degree, certification or licensure)}

Attending study group

Listening to language $\mathrm{CD}$

Organizing notes

Reading
Reading/sending e-mail

Studying

Writing paper/essay 
Table 1C Description of the variables

\begin{tabular}{|c|c|c|}
\hline VARIABLES & Definition & Source \\
\hline \multicolumn{3}{|l|}{ Dependent variables } \\
\hline \multirow[t]{2}{*}{$Y_{i j}$} & Dummy variable equal to 1 if the respondent has spent & ATUS \\
\hline & $\begin{array}{l}\text { a positive amount of time in informal (formal) education, } \\
\text { and } 0 \text { otherwise. }\end{array}$ & $2003-15$ \\
\hline FormalEdu $u_{i j}$ & $\begin{array}{l}\text { Amount of time (in minutes) spent in formal } \\
\text { education. }\end{array}$ & $-/ /-$ \\
\hline InformalEdu $u_{i j}$ & $\begin{array}{l}\text { Amount of time (in minutes) spent in informal } \\
\text { education. }\end{array}$ & $-/ /-$ \\
\hline \multicolumn{3}{|c|}{ Explanatory and control variables } \\
\hline ForeignBorn $_{i j}$ & $\begin{array}{l}\text { Dummy equal to } 1 \text { if the respondent was born abroad, } 0 \\
\text { otherwise. }\end{array}$ & CPS \\
\hline Age & Age in years & $-/ /-$ \\
\hline Age squared & The square of age. & $-/ /-$ \\
\hline Female & $\begin{array}{l}\text { Dummy equal to } 1 \text { if the respondent is female, } 0 \\
\text { otherwise. }\end{array}$ & $-/ /-$ \\
\hline Married & $\begin{array}{l}\text { Dummy equal to } 1 \text { if the respondent is married, } 0 \\
\text { otherwise. }\end{array}$ & $-/ /-$ \\
\hline $\begin{array}{l}\text { No children, children } \\
\text { 0-2 years, children } \\
\text { 3-5 years, children } \\
\text { 6-12 years, children } \\
13-17 \text { years }\end{array}$ & $\begin{array}{l}5 \text { dummy variables equal to } 1 \text { if the respondent has a } \\
\text { child in these age groups, } 0 \text { otherwise. }\end{array}$ & $-/ /-$ \\
\hline $\begin{array}{l}\text { Less than elementary, } \\
\text { Elementary, Middle } \\
\text { Secondary, Degree } \\
\text { Post graduate }\end{array}$ & $\begin{array}{l}6 \text { dummy variables for each of the educational level } \\
\text { specified. }\end{array}$ & $-/ /-$ \\
\hline Holiday & $\begin{array}{l}\text { Dummy equal to } 1 \text { if the diary day is (Sunday, New } \\
\text { Year's Day, Easter, Memorial Day, } 4^{\text {th }} \text { of July or } \\
\text { Christmas), } 0 \text { otherwise. }\end{array}$ & $\begin{array}{l}\text { ATUS } \\
2003-15\end{array}$ \\
\hline Employed & $\begin{array}{l}\text { In the reference week, worked at least } 1 \text { hour as a paid } \\
\text { employee or self-employed. It also includes those in job } \\
\text { but not at work in the reference week and the unpaid family } \\
\text { workers. }\end{array}$ & CPS \\
\hline Unemployed & $\begin{array}{l}\text { Individual available for work at the reference week and those } \\
\text { making an effort to find a job in the } 3 \text { weeks preceding the } \\
\text { reference week. }\end{array}$ & $-/ /-$ \\
\hline Not in labor force & $\begin{array}{l}\text { Individual that had not actively looked for a job in the } 3 \\
\text { weeks preceding the reference week. }\end{array}$ & $-/ /-$ \\
\hline Non English speaking & These dummies are defined following Bleakley and Chin & ATUS \\
\hline $\begin{array}{l}\text { English speaking } \\
\text { English official }\end{array}$ & $(2004)$ & $2003-15$ \\
\hline
\end{tabular}




\section{Appendix 2: Theoretical model}

\section{A2.1 Determination of the trajectories of informal education and human capital} accumulation

In this section, we describe in details the analysis of the optimal trajectories of investment in informal education by the agent and the subsequent accumulation of human capital. Let us start from the fact that, once time devoted to education, $e_{t}$, is known, the amounts of time allocated respectively to consumption, $c_{t}$, and work, $l_{t}$, are determined by the budget constraint $c_{t} \leq$ $w\left(h_{t}\right) l_{t}$ and the time constraint $l_{t}+c_{t}+e_{t} \leq \bar{\theta}$. Knowing that both constraints will always be binding, we can combine them, getting

$$
\text { (A1) } c_{t}=w\left(h_{t}\right) l_{t}=w\left(h_{t}\right)\left(\bar{\theta}-e_{t}-c_{t}\right)=\frac{w\left(h_{t}\right)\left(\bar{\theta}-e_{t}\right)}{1+w\left(h_{t}\right)}
$$

and the utility of the agent at date $t$ may be written as:

$$
\bar{u}\left(h_{t}, e_{t}\right)=u\left(\frac{w\left(h_{t}\right)\left(\bar{\theta}-e_{t}\right)}{1+w\left(h_{t}\right)}\right)
$$

Then, the agent's optimal choice is the solution to the dynamic problem:

$$
\max _{e_{t}} \int_{0}^{T} e^{-\rho t} u\left(\frac{w\left(h_{t}\right)\left(\bar{\theta}-e_{t}\right)}{1+w\left(h_{t}\right)}\right) d t
$$

where the control variable, $e_{t}$, meets the constraint $0 \leq e_{t} \leq \bar{\theta}$ and the state variable measuring human capital at time $t, h_{t}$, follows the movement equation:

$$
\grave{h}_{t}=\operatorname{amax}\left(e_{t}-\varepsilon, 0\right)
$$

There is no terminal condition. The current value Lagrangian of this problem is:

$$
\mathcal{L}=u\left(\frac{w\left(h_{t}\right)\left(\bar{\theta}-e_{t}\right)}{1+w\left(h_{t}\right)}\right)+\lambda_{t} \operatorname{amax}\left(e_{t}-\varepsilon, 0\right)+\mu_{t}^{0} e_{t}+\mu_{t}^{1}\left(\bar{\theta}-e_{t}\right)
$$

where $\lambda_{t}$ is the cofactor associated to the movement equation, $\mu_{t}^{0}$ is the Lagrange multiplier associated to the constraint $0 \leq e_{t}$, and $\mu_{t}^{1}$ is the Lagrange multiplier associated to the constraint $e_{t} \leq \bar{\theta}$.

Following the Maximum Principle, the conditions for an optimum are:

$$
\begin{aligned}
& \frac{\partial \mathcal{L}}{\partial e_{t}}=-\frac{w\left(h_{t}\right)}{1+w\left(h_{t}\right)} u^{\prime}\left(c_{t}\right)+\lambda_{t} a \mathbb{I}\left(e_{t}-\varepsilon\right)+\mu_{t}^{0}-\mu_{t}^{1}=0 \\
& \text { (A3) } \dot{\lambda}_{t}-\rho \lambda_{t}=-\frac{\partial \mathcal{L}}{\partial h_{t}}=-\frac{\left(\bar{\theta}-e_{t}\right) w^{\prime}\left(h_{t}\right)}{\left(1+w\left(h_{t}\right)\right)^{2}} u^{\prime}\left(c_{t}\right)
\end{aligned}
$$

where $\mathbb{I}()$ is the indicator function for positive values: $\mathbb{I}\left(e_{t}-\varepsilon\right)=0$ if $e_{t}-\varepsilon \leq 0$ and $\mathbb{I}\left(e_{t}-\varepsilon\right)=1$ if $e_{t}-\varepsilon>0$. We also have the transversality condition:

$$
\lambda_{T}=0
$$


Note that $e_{t}<\varepsilon \Rightarrow e_{t}=0$. More precisely, if $e_{t}<\varepsilon$, then $\mu_{t}^{1}=0$ and $\mathbb{I}\left(e_{t}-\varepsilon\right)=0$, so that (A2) becomes

$$
\mu_{t}^{0}=\frac{w\left(h_{t}\right)}{1+w\left(h_{t}\right)} u^{\prime}\left(c_{t}\right)>0
$$

which implies that no time is allocated to education, $e_{t}=0$. Then, if for some date $\tau, \lim _{t \rightarrow \tau} e_{t}=$ $\varepsilon$, at $\tau$ time devoted to education jumps to zero: $e_{\tau}=0$. This jump is the straightforward consequence of the fact that, as soon as time devoted to education falls below $\varepsilon$, education does not produce human capital any longer. Then, the agent decides not to engage in education for not sparing time.

Moreover, $e_{t}=0$ implies that no human capital is accumulated, $\grave{h}_{t}=0$, so that $h_{t}$ does not change. Then, with an invariant stock of human capital, the agent always takes the same decision: as soon as the agent has decided not to engage in education at some date, she will not engage in education in the future.

In addition, the terminal condition $\lambda_{T}=0$ also implies $\mu_{T}^{0}>0$ and then $\lim _{t \rightarrow T} e_{t}=\varepsilon$, with the consequence that $e_{T}=0$.

If $\varepsilon<e_{t}<\bar{\theta}$, then $\mu_{t}^{0}=\mu_{t}^{1}=0$, so that (A2) becomes:

$$
\text { (A4) } \lambda_{t}=\frac{w\left(h_{t}\right) / a}{1+w\left(h_{t}\right)} u^{\prime}\left(c_{t}\right)
$$

and then, calculating the log derivative with respect to time and using the movement equation:

$$
\frac{\dot{\lambda}_{t}}{\lambda_{t}}=\frac{w^{\prime}\left(h_{t}\right)}{w\left(h_{t}\right)\left(1+w\left(h_{t}\right)\right)} \grave{h}_{t}+\frac{c_{t} u^{\prime \prime}\left(c_{t}\right)}{u^{\prime}\left(c_{t}\right)} \frac{\dot{c}_{t}}{c_{t}}=\frac{\left(e_{t}-\varepsilon\right) a w^{\prime}\left(h_{t}\right)}{w\left(h_{t}\right)\left(1+w\left(h_{t}\right)\right)}-\eta\left(c_{t}\right) \frac{\dot{c}_{t}}{c_{t}}
$$

where $-\eta\left(c_{t}\right)=-c_{t} u^{\prime \prime}\left(c_{t}\right) / u^{\prime}\left(c_{t}\right)>0$. Calculating the log derivative of (A1), we get:

$$
\frac{\dot{c}_{t}}{c_{t}}=\frac{w^{\prime}\left(h_{t}\right)}{w\left(h_{t}\right)\left(1+w\left(h_{t}\right)\right)} \grave{h}_{t}-\frac{\dot{e}_{t}}{\bar{\theta}-e_{t}}=\frac{\left(e_{t}-\varepsilon\right) a w^{\prime}\left(h_{t}\right)}{w\left(h_{t}\right)\left(1+w\left(h_{t}\right)\right)}-\frac{\dot{e}_{t}}{\bar{\theta}-e_{t}}
$$

so that:

$$
\text { (A5) } \frac{\dot{\lambda}_{t}}{\lambda_{t}}=\frac{\left(1-\eta\left(c_{t}\right)\right) a w^{\prime}\left(h_{t}\right)\left(e_{t}-\varepsilon\right)}{w\left(h_{t}\right)\left(1+w\left(h_{t}\right)\right)}+\frac{\eta\left(c_{t}\right)}{\bar{\theta}-e_{t}} \dot{e}_{t}
$$

Using (A4), we can rewrite (A3) as:

$$
\dot{\lambda}_{t}-\rho \lambda_{t}=-\frac{\left(\bar{\theta}-e_{t}\right) w^{\prime}\left(h_{t}\right)}{\left(1+w\left(h_{t}\right)\right)^{2}} u^{\prime}\left(c_{t}\right)=-\lambda_{t} \frac{\left(\bar{\theta}-e_{t}\right) a w^{\prime}\left(h_{t}\right)}{w\left(h_{t}\right)\left(1+w\left(h_{t}\right)\right)}
$$

And then:

$$
\text { (A6) } \frac{\dot{\lambda}_{t}}{\lambda_{t}}=\rho-\frac{\left(\bar{\theta}-e_{t}\right) a w^{\prime}\left(h_{t}\right)}{w\left(h_{t}\right)\left(1+w\left(h_{t}\right)\right)}
$$

so that, combining (A5) and (A6) we get: 


$$
\frac{\eta\left(c_{t}\right)}{\bar{\theta}-e_{t}} \dot{e}_{t}=\rho-\frac{\left(\bar{\theta}-e_{t}\right) a w^{\prime}\left(h_{t}\right)}{w\left(h_{t}\right)\left(1+w\left(h_{t}\right)\right)}-\frac{\left(1-\eta\left(c_{t}\right)\right) a w^{\prime}\left(h_{t}\right)\left(e_{t}-\varepsilon\right)}{w\left(h_{t}\right)\left(1+w\left(h_{t}\right)\right)}
$$

leading to the equation defining the optimal trajectory for the education variable:

$$
\text { (A7) } \dot{e}_{t}=\frac{\bar{\theta}-e_{t}}{\eta\left(c_{t}\right)}\left[\rho-\frac{\left[\bar{\theta}-\varepsilon-\eta\left(c_{t}\right)\left(e_{t}-\varepsilon\right)\right] a w^{\prime}\left(h_{t}\right)}{w\left(h_{t}\right)\left(1+w\left(h_{t}\right)\right)}\right]
$$

Along a trajectory $\left(h_{t}, e_{t}\right)$ starting from the initial level of human capital, $h_{0}$, and the initial choice of education, $e_{0}$, we have:

$$
\text { (A8) } \frac{d e_{t}}{d h_{t}}=\frac{\dot{e}_{t}}{\grave{h}_{t}}=\frac{\dot{e}_{t}}{a\left(e_{t}-\varepsilon\right)}=\frac{\bar{\theta}-e_{t}}{\eta\left(c_{t}\right)\left(e_{t}-\varepsilon\right)}\left[\frac{\rho}{a}-\frac{\left[\bar{\theta}-\varepsilon-\eta\left(c_{t}\right)\left(e_{t}-\varepsilon\right)\right] w^{\prime}\left(h_{t}\right)}{w\left(h_{t}\right)\left(1+w\left(h_{t}\right)\right)}\right]
$$

Then, knowing that $\eta\left(c_{t}\right)>0$ and $e_{t} \leq \bar{\theta}$ :

$$
\begin{aligned}
& \frac{d e_{t}}{d h_{t}}=0 \Leftrightarrow \dot{e}_{t}=0 \Leftrightarrow e_{t}=\bar{\theta} \text { or } e_{t}=Z\left(h_{t}\right) \\
& \frac{d e_{t}}{d h_{t}} \gtreqless 0 \Leftrightarrow \dot{e}_{t} \gtreqless 0 \Leftrightarrow e_{t}<\bar{\theta} \text { and } e_{t} \gtreqless Z\left(h_{t}\right)
\end{aligned}
$$

where $Z\left(h_{t}\right)$ is the function giving the value of $e_{t}$ equalizing the value of the bracketed term in (A8) to 0:

(A9) $Z\left(h_{t}\right)=\bar{\theta}+\frac{\left(1-\eta\left(c_{t}\right)\right)(\bar{\theta}-\varepsilon)}{\eta\left(c_{t}\right)}-\frac{\rho w\left(h_{t}\right)\left(1+w\left(h_{t}\right)\right)}{a \eta\left(c_{t}\right) w^{\prime}\left(h_{t}\right)}$

Let us now focus on the iso-elastic case, with $\eta\left(c_{t}\right)=\eta \in[0,1]$ and $w\left(h_{t}\right)=\left(h_{t}\right)^{\gamma}$ with $\gamma \in$ $[0,1]$. Equations (A7), (A8) and (A9) can be re-written as:

$$
\begin{aligned}
& \text { (A7.1) } \dot{e}_{t}=\frac{\bar{\theta}-e_{t}}{\eta}\left[\rho-\frac{\left[\bar{\theta}-\varepsilon-\eta\left(e_{t}-\varepsilon\right)\right] a \gamma}{h_{t}\left(1+\left(h_{t}\right)^{\gamma}\right)}\right] \\
& \text { (A8.1) } \frac{d e_{t}}{d h_{t}}=\frac{\bar{\theta}-e_{t}}{\eta\left(e_{t}-\varepsilon\right)}\left[\frac{\rho}{a}-\frac{\left[\bar{\theta}-\varepsilon-\eta\left(e_{t}-\varepsilon\right)\right] \gamma}{h_{t}\left(1+\left(h_{t}\right)^{\gamma}\right)}\right] \\
& \text { (A9.1) } Z\left(h_{t}\right)=\bar{\theta}+\frac{(1-\eta)(\bar{\theta}-\varepsilon)}{\eta}-\frac{\rho h_{t}\left(1+\left(h_{t}\right)^{\gamma}\right)}{a \eta \gamma}
\end{aligned}
$$

The dynamics of the agent's choice are represented in Figure 1.

The black thick curve represents the highest possible trajectory of investment in education where we have $\dot{e}_{t}=0$. This curve has two parts: a horizontal part, corresponding to the time constraint, $e_{t}=\bar{\theta}$, where the agent allocates all the available time to education and a decreasing part, corresponding to $e_{t}=Z\left(h_{t}\right)$. This line crosses the horizontal line $e_{t}=\varepsilon-$ that is the level of investment in education below which human capital accumulation stops at a threshold level of human capital equal to $h_{t}=h^{+}$; for any level of initial human capital $h_{t}>h^{+}$, agents will never invest in education. 


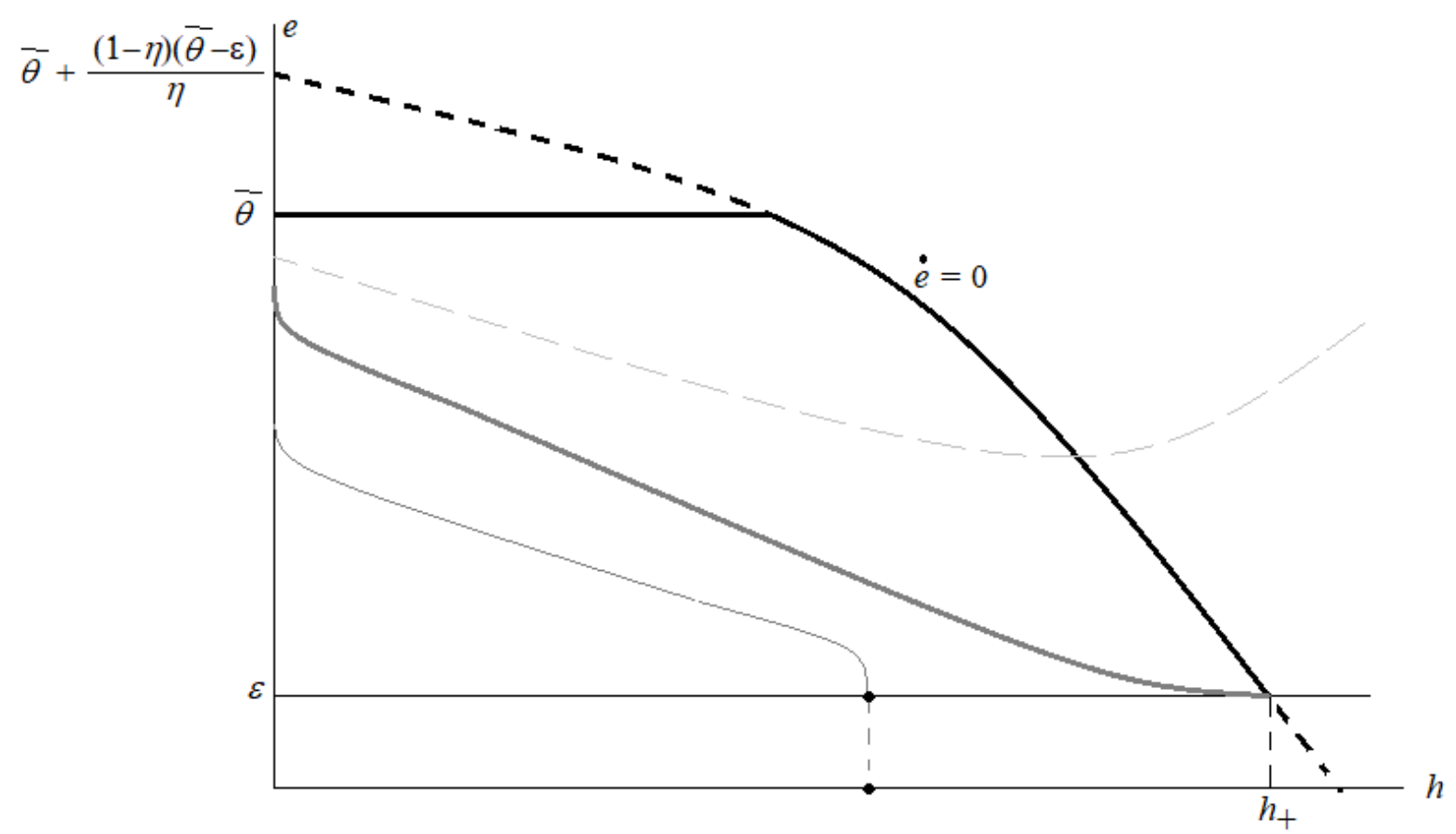

For meeting the transversality condition, a trajectory must end on the horizontal axis, knowing that if, at some $\tau<T, e_{\tau}=\varepsilon$, then $e_{t}=0$ for every $\left.\left.t \in\right] \tau, T\right]$. This rules out all the trajectories that are above the curve $\dot{e}_{t}=0$, as along these trajectories $e_{t}$ increases and then moves away from the horizontal axis. This also rules out the trajectories that are above the thick grey curve, which is the trajectory crossing the intersection of the curve $\dot{e}_{t}=0$ at $h_{t}=h^{+}$, as these trajectories cross the curve $\dot{e}_{t}=0$ and then end with $e_{t}$ increasing (an example is the thin dotted grey line). A typical trajectory has the shape given by the thin grey line. If the agent's human capital is not too high $\left(h_{t}<h^{+}\right)$, the agent starts with a time devoted to education $e_{t}>$ $\varepsilon$. Then, the time devoted to education decreases along the trajectory until $e_{t}=\varepsilon$; at that time, the agent jumps to $e_{t}=0$ until the end of her life. The agent chooses the highest possible trajectory which implies that, if the life is not too long, she ends at $e_{T}=\varepsilon$. If her lifetime is longer, the agent chooses the limit trajectory and, at some age $<T$, we have $\lim _{t \rightarrow \tau} e_{t}=\varepsilon$ and $h_{\tau}=h^{+}$. Then, for the end of her life, $e_{t}=0$ and the agent stops engaging in education.

\section{A2.2 Impact of parameters}

The analysis of the impact of parameters is carried out in the isoelastic case and their signs are derived under the assumption that $\dot{e}_{t}<0$. We choose parameters that may significantly differ between the two populations of interest, immigrants and natives: initial level of human capital, 
$h_{0}$, efficiency of education, $a$, fixed cost of education, $\varepsilon$, time availability, $\bar{\theta}$, time preference, $\rho$.

Before looking at these impacts, we need to calculate some derivatives with respect to the state variable, $h_{t}$, and the control variables, $e_{t}$. The derivatives with respect to $h_{t}$ are:

$$
\begin{gathered}
\frac{\partial \dot{e}_{t}}{\partial h_{t}}=\frac{\left(\bar{\theta}-e_{t}\right)\left[\bar{\theta}-\varepsilon-\eta\left(e_{t}-\varepsilon\right)\right] a \gamma\left(1+(1+\gamma)\left(h_{t}\right)^{\gamma}\right)}{\eta\left[h_{t}\left(1+\left(h_{t}\right)^{\gamma}\right)\right]^{2}}>0 \\
\frac{\partial}{\partial h_{t}}\left(\frac{d e_{t}}{d h_{t}}\right)=\frac{1}{a\left(e_{t}-\varepsilon\right)} \frac{\partial \dot{e}_{t}}{\partial h_{t}}>0
\end{gathered}
$$

The derivatives with respect to $e_{t}$ are:

$$
\begin{gathered}
\frac{\partial \dot{e}_{t}}{\partial e_{t}}=\frac{\left(\bar{\theta}-e_{t}\right) \eta a \gamma}{\eta h_{t}\left(1+\left(h_{t}\right)^{\gamma}\right)}-\frac{1}{\eta}\left[\rho-\frac{\left[\bar{\theta}-\varepsilon-\eta\left(e_{t}-\varepsilon\right)\right] a \gamma}{h_{t}\left(1+\left(h_{t}\right)^{\gamma}\right)}\right]>0 \\
\frac{\partial}{\partial e_{t}}\left(\frac{d e_{t}}{d h_{t}}\right)=\frac{1}{a\left(e_{t}-\varepsilon\right)} \frac{\partial \dot{e}_{t}}{\partial e_{t}}-\frac{\dot{e}_{t}}{a\left(e_{t}-\varepsilon\right)^{2}}>0
\end{gathered}
$$

\section{Impact of a change in the initial level of human capital, $h_{0}$ :}

Let the initial level of human capital increase from $h_{0}$ to $h_{0}+\delta h_{0}$, with $\delta h_{0}>0$. If the agent were choosing the trajectory starting at the initial level of education, $e_{0}$, this new trajectory would be on the right of the initial one so that, for every value of $e_{t}, h_{t}$ is higher on the new trajectory than on the initial one. Then, $\partial \dot{e}_{t} / \partial h_{t}$ being negative, $e_{t}$ decreases on the new trajectory at a lower speed than on the initial one and the new trajectory takes more time. The consequence is that, for reaching the target $e_{T}=\varepsilon$, the agent starts from a higher value of $e_{0}$. An agent who has a higher initial level of human capital chooses to devote less time to education. Intuitively, decreasing returns to human capital imply that an agent who starts with a higher level of human capital has lower future returns from extra human capital generated by extra education, and then has a lower incentive to devote time to education.

\section{Impact of a change in the efficiency of education, $a$ :}

Differentiating (A7.1) and (A8.1) with respect to $a$, we get:

$$
\begin{gathered}
\frac{\partial \dot{e}_{t}}{\partial a}=-\frac{\left(\bar{\theta}-e_{t}\right)\left[\bar{\theta}-\varepsilon-\eta\left(e_{t}-\varepsilon\right)\right] \gamma}{\eta h_{t}\left(1+\left(h_{t}\right)^{\gamma}\right)}<0 \\
\frac{\partial}{\partial a}\left(\frac{d e_{t}}{d h_{t}}\right)=-\frac{\rho\left(\bar{\theta}-e_{t}\right)}{\eta a^{2}\left(e_{t}-\varepsilon\right)}<0
\end{gathered}
$$

If $a$ increases, then the slope $d e_{t} / d h_{t}$ of every trajectory is more negative implying that, for the same starting point $\left(h_{0}, e_{0}\right)$, the new trajectory is below the old one. Consequently, for every level $h_{t}$ of human capital, $e_{t}$ is lower (or, reciprocally, for every $e_{t}$, the value of $h_{t}$ on the trajectory is lower). The direct effect of an increase in $a$ on $\dot{e}_{t}$ is negative; moreover, $h_{t}$ 
being lower and $\partial \dot{e}_{t} / \partial h_{t}>0$, the indirect effect is also negative. Along the new trajectory, $e_{t}$ decreases at a higher speed ( $-\dot{e}_{t}>0$ is higher) and the new trajectory takes less time. Then, for reaching the target $e_{T}=\varepsilon$, the agent starts from a higher value of $e_{0}$.

An agent who is more efficient in using education for generating human capital devotes more time to education. Intuitively, a more efficient education generates more human capital and then increases the future returns to education, increasing the incentive to educate.

Impact of a change in the fixed cost of education, $\varepsilon$ :

Differentiating (A7.1) and (A8.1) with respect to $\varepsilon$, we get:

$$
\begin{gathered}
\frac{\partial \dot{e}_{t}}{\partial \varepsilon}=\frac{\left(\bar{\theta}-e_{t}\right)(1-\eta) a \gamma}{\eta h_{t}\left(1+\left(h_{t}\right)^{\gamma}\right)}>0 \\
\frac{\partial}{\partial \varepsilon}\left(\frac{d e_{t}}{d h_{t}}\right)=\frac{\bar{\theta}-e_{t}}{\eta\left(e_{t}-\varepsilon\right)^{2}}\left[\frac{\rho}{a}-\frac{(\bar{\theta}-\varepsilon) \gamma}{h_{t}\left(1+\left(h_{t}\right)^{\gamma}\right)}\right]<0
\end{gathered}
$$

If $\varepsilon$ increases, then the slope $d e_{t} / d h_{t}$ of every trajectory is more negative implying that, for the same starting point $\left(h_{0}, e_{0}\right)$, the new trajectory is below the old one. Consequently, for every level $h_{t}$ of human capital, $e_{t}$ is lower (or, reciprocally, for every $e_{t}$, the value of $h_{t}$ on the trajectory is lower). The direct effect of an increase in $\varepsilon$ on $\dot{e}_{t}$ is positive, but $h_{t}$ being lower and $\partial \dot{e}_{t} / \partial h_{t}<0$, there a positive indirect effect. Then, we cannot tell whether the new trajectory takes more or less time than the new one and the impact of $\varepsilon$ on $e_{t}$ is ambiguous.

Impact of a change in time availability, $\bar{\theta}$ :

Differentiating (A7.1) and (A8.1) with respect to $\bar{\theta}$, we get:

$$
\begin{gathered}
\frac{\partial \dot{e}_{t}}{\partial \bar{\theta}}=\frac{1}{\eta}\left[\rho-\frac{\left[\bar{\theta}-\varepsilon-\eta\left(e_{t}-\varepsilon\right)\right] a \gamma}{h_{t}\left(1+\left(h_{t}\right)^{\gamma}\right)}\right]-\frac{\left(\bar{\theta}-e_{t}\right) a \gamma}{\eta h_{t}\left(1+\left(h_{t}\right)^{\gamma}\right)}<0 \\
\frac{\partial}{\partial \bar{\theta}}\left(\frac{d e_{t}}{d h_{t}}\right)=\frac{1}{a\left(e_{t}-\varepsilon\right)} \frac{\partial \dot{e}_{t}}{\partial \bar{\theta}}<0
\end{gathered}
$$

If $\bar{\theta}$ increases, then the slope $d e_{t} / d h_{t}$ of every trajectory is more negative implying that, for the same starting point $\left(h_{0}, e_{0}\right)$, the new trajectory is below the old one. Consequently, for every level $h_{t}$ of human capital, $e_{t}$ is lower (or, reciprocally, for every $e_{t}$, the value of $h_{t}$ on the trajectory is lower). Then, the higher value of $\bar{\theta}$ implies a more negative value of $\dot{e}_{t}$, both directly because $\partial \dot{e}_{t} / \partial \bar{\theta}<0$ and indirectly because $h_{t}$ is lower and $\partial \dot{e}_{t} / \partial h_{t}>0$. Along the new trajectory, $e_{t}$ decreases at a higher speed $\left(-\dot{e}_{t}>0\right.$ is higher) and the new trajectory takes less time.

Then, for reaching the target $e_{T}=\varepsilon$, the agent starts from a higher value of $e_{0}$. 
An agent who has more time available devotes some part of the extra time available for getting more education: time devoted to education behaves like a normal good

\section{Impact of a change in the rate of time preference, $\rho$ :}

Differentiating (A7.1) and (A8.1) with respect to $\rho$, we get:

$$
\begin{gathered}
\frac{\partial \dot{e}_{t}}{\partial \rho}=\frac{\bar{\theta}-e_{t}}{\eta}>0 \\
\frac{\partial}{\partial \rho}\left(\frac{d e_{t}}{d h_{t}}\right)=\frac{\bar{\theta}-e_{t}}{\eta a\left(e_{t}-\varepsilon\right)}>0
\end{gathered}
$$

If $\rho$ increases, then the slope $d e_{t} / d h_{t}$ of every trajectory is less negative implying that, for the same starting point $\left(h_{0}, e_{0}\right)$, the new trajectory is above the old one. Consequently, for every level $h_{t}$ of human capital, $e_{t}$ is higher (or, reciprocally, for every $e_{t}$, the value of $h_{t}$ on the trajectory is higher). Then, the higher value of $\rho$ implies a less negative value of $\dot{e}_{t}$, both directly because $\partial \dot{e}_{t} / \partial \rho>0$ and indirectly because $h_{t}$ is higher and $\partial \dot{e}_{t} / \partial h_{t}>0$. Along the new trajectory, $e_{t}$ decreases at a lower speed $\left(-\dot{e}_{t}<0\right.$ is higher) and the new trajectory takes more time. Then, for reaching the target $e_{T}=\varepsilon$, the agent starts from a lower value of $e_{0}$.

An agent who has a higher rate of time preference devotes less time to education because, as she discounts less the future, the current aggregate value of the future gains generated by education is higher. 